How to Produce a Readable Electrocardiogram

Bertram A. Bradlow. Pp. xxiii +182 , illustrated. Springfield, Illinois: Charles C. Thomas. 1964. $\$ 8.50$.

This book deals with the technique of recording electrocardiograms and intentionally omits discussion of their interpretation. The author has written a thorough and readable account, which rightly leaves nothing to the imagination and does not flinch from emphasising what to some may appear the obvious. This is the correct way to teach sound technique, and these pages have a message equally for cardiac technician, house physician or consultant physicianfor anyone, that is, who at any time uses an ECG machine.

After a simple description of electrocardiograph instruments (the graph is the thing that writes, the gram the tracing that emerges) the author deals in detail with the process of recording, the sources of error and artefact, the conduct of the exercise test, and finally the mounting and filing of records. He devotes much space to the importance of the one millivolt standardisation signal and to alterations produced by overdamping-distortion of the ST takeoff, widening of the QRS complex and misleading changes in $\mathbf{R}$ and $\mathbf{S}$ wave amplitude. Numerous causes of artefacts are listed, from common ones such as somatic tremor or wandering baseline, to more recherché ones like hiccough or arterial pulsation. Methods of eliminating $\mathrm{AC}$ interference are given fully, but an electrical explanation of the phenomenon might be added for the benefit of those to whom it remains a mystery why a well insulated mains cable crossing the patient lead should cause distortion, or why the patient's shaver lying inert on his locker must be actually unplugged from the wall socket.

The book is liberally furnished with illustrations of good and bad tracings which make their point uncompromisingly. Some of the bad ones are indeed so monstrous that many a reader will glow in selfrighteousness at his inability to perpetuate such crimes. Though other books with the same intent may be in existence, the reviewer has not come across one. It would certainly be difficult to produce a better, and Dr. Bradlow has done a good job.

\section{Research Methods in Surgery}

Edited by WALTER F. BALlinger II. With twentyfive contributing authors. Pp. xvii +400 , illustrated. London: J. \& A. Churchill. 1964. 75s. This book, in the words of Dr. John H. Gibbon, Jnr., who writes the foreword, is "concerned with surgical research, the philosophy and technique of research in many different fields" being described. There are early chapters describing in general the problems of animal research, of laboratory design and equipment, and of the design of experiments. These chapters include one which enumerates the methods by which money can be obtained for research programmes in the United States. The information is necessarily apposite only for the American reader, but is nevertheless of interest to, and will arouse admiring envy in the breasts of, British workers.

There are chapters detailing techniques of research in most branches of surgery with the notable exception of urology. These chapters include cardiac, pulmonary, gastro-intestinal, and endocrine surgery. Metabolic studies. shock, wound healing, thrombo- genesis, immunology and organ preservation ancे transplantation all receive detailed treatment. Therळ is a chapter on cancer investigation which is perhap? not surprisingly superficial compared to the treatment of the other topics. Finally, there is a valuables. appraisal of basic electronic equipment and a chaptese on how to evaluate data.

The printing and line drawings are clear. The volume is bound to be a valuable addition to the armamentarium of any surgical laboratory, even if only as a guide to the literature of techniques investigation.

\section{Access and Exposure in Abdominal Surgery}

H. A. F. Dudley and P. F. Jones. Pp. xii $+14 \sqrt{\text { w }}$ illustrated. London: Lloyd-Luke. 1964. 25s. خ The trend of fashion offers technique a rather humble place in surgical deliberations and surgica. conferences are given to offering us minute analyses of the results of operations, of whose details we remain in ignorance. Certainly the patient himse likes to feel he is in the hands of a punctilious crafts man. It is quite refreshing to come across a wholes textbook entirely devoted to the making and repair of abdominal incisions. Although everyone will agree that practical training is perhaps best carried out bo first-hand example, there is a place in a training programme for an authoritative account of standarf procedures, and that offered by these authors prow bably represents a very good average of the methods most commonly used in this country today. The young surgeon who follows their lessons is not likel to be regarded as slap-dash by his professiongefs, visitors. It is notoriously difficult to write dow $\overline{\mathrm{g}}$. complete account of a practical task. The authog are to be congratulated upon the hard work they havs put into this task. Their text will certainly be help ful to the postgraduate student of surgery.

\section{Modern Trends in Orthopadics. Volume 4}

Edited by J. M. P. Clark. Pp. viii +254 , illus

trated. London: Butterworth. 1964. 60s.

The importance of this latest volume in the Muder Trends series is expressed in its sub-title "Science of Fractures". It thus acknowledges that furthes advances in the treatment of fractures depend upon. a study of basic sciences and research in this field

The core of the book is the chapter by Burwell on the biology of bone transplantation. This is a closel\& reasoned account of current views concerning immunological, inductive and remodelling mechanisms in relation to grafting. Having been an orthopædis surgeon as well as a research worker, the authos includes a helpful glossary, as well as summarising his conclusions, to ease the passage of the less. academically qualified reader.

Before this, come a series of chapters on such subjects as molecular structure, calcification, histolog of fracture repair and blood supply of bone. Th: authoritative text of the last is so crammed with references that the meaning is sometimes obscurees, 187 being listed at the end. The aims of a boow designed to present important academic subjects to those working in an applied field (in this case orthopædic surgery) may be better served by simplef and more imaginative writing. By contrast the writer on the molecular structure of bone remarks: "ThE life of a soft tissue is therefore a perpetual figh 